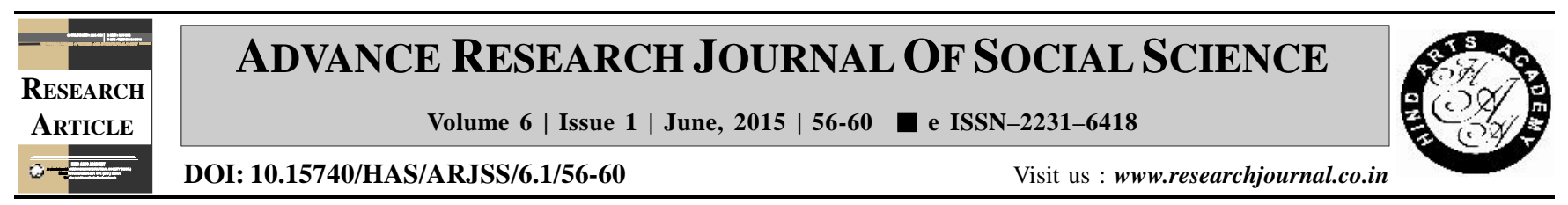

\title{
Socio-economic status of muslim women in Lakhimpur district of Assam
}

Swapna Dutta

Lakhimpur Telahi Kamalabaria College, Azad, LAKHIMPUR (ASSAM) INDIA

(Email: swapnadutta544@gmail.com)

\begin{tabular}{lrl}
\multicolumn{2}{l}{ ARTICLE INFO : } \\
$\begin{array}{lrl}\text { Received } & : & 12.02 .2015 \\
\text { Revised } & : & 23.04 .2015 \\
\text { Accepted } & : & 07.05 .2015\end{array}$
\end{tabular}

KEY WORDS :

Socio-economic status, Muslim women, Illiteracy, Poverty, Awareness

HOW TO CITE THIS ARTICLE :

Dutta, Swapna (2015). Socio-economic status of muslim women in Lakhimpur district of Assam. Adv. Res. J. Soc. Sci., 6 (1) : 56-60.

\begin{abstract}
The study was conducted on socio-economic status of muslim women in urban areas of Lakhimpur District in Assam. One hundred twenty muslim women were purposely selected from two muslim dominated areas of Lakhimpur District. The information was gathered with the help of questionnaire cum interview technique. Interview questionnaire contained comprehensive questions relate to present study. The data were presented in tabular form. The study revealed that more than half of muslim women $(67.5 \%)$ were below metric. Only 5.83 per cent of women were above metric. Analysis of literacy amongst muslim women highlights some important implication in the context of their socio-economic status. The educational backwardness of women makes them the largest group hindering the process of social change. Information was obtained about family income which is an important index of the socio-economic background. It was found that majority of sample household belongs to the monthly income up to the level of Rs. 10000/- only. It indicates a condition in which a person fails to maintain a living standard adequate for his physical and mental efficiency in present day situation. Further it has been found that the economic condition of the sample household, the majority of them i.e., 51.66 per cent were in poverty line which affects the woman most because the female members in the family are denied education, healthcare, nutritious food due to poverty. Unhygienic sanitation was also seen because of poverty. It was seen that lack of education or poor educational status resulted in the married women depending on their husbands for undertaking any decisions concerning the family. Poor educational level also affected their awareness of certain factors affecting their lives such as family planning, right to information act, domestic violence laws etc.
\end{abstract}

